\title{
Mesoporous Reduced Graphene Oxide as a High Capacity Cathode for Aluminum Batteries
}

\author{
Jasmin Smajic ${ }^{1}$, Amira Alazmi ${ }^{1}$, Nitinkumar Batra ${ }^{1}$, Tamilarasan Palanisamy ${ }^{1}$, Dalaver H. Anjum², \\ Pedro M. F. J. Costa ${ }^{1 *}$ \\ ${ }^{1}$ King Abdullah University of Science and Technology, Physical Science and Engineering Division, Thuwal 23955-6900, Saudi Arabia \\ ${ }^{2}$ King Abdullah University of Science and Technology, Core Labs, Thuwal 23955-6900, Saudi Arabia
}

\begin{abstract}
Research in the field of aluminum batteries has focused heavily on electrodes made of carbonaceous materials. It is believed that a high structural quality of graphitic carbons and/or specific surface areas of $>1000 \mathrm{~m}^{2} \mathrm{~g}^{-1}$ are key factors to obtain optimal performance and cycling stability. Still, the capacities reported for these multivalent systems remain stubbornly low, particularly when compared to the $>300$ $\mathrm{mAh} \mathrm{g}^{-1}$ regularly attained by commercial lithium-ion batteries.

Here, we present an aluminum chloride battery in which reduced graphene oxide (RGO) powder, dried under supercritical conditions, is used as the active cathode material and niobium foil as the current collector. With a specific surface area of just $364 \mathrm{~m}^{2} \mathrm{~g}^{-1}$, the RGO enables a gravimetric capacity of 171 $\mathrm{mAh} \mathrm{g}^{-1}$ at $100 \mathrm{~mA} \mathrm{~g}^{-1}$ and remarkable stability over a wide range of current densities (<15\% decrease over 100 cycles in the interval $\left.100-20,000 \mathrm{~mA} \mathrm{~g}^{-1}\right)$. These properties, up to now achieved only with much larger surface area materials, result from the cathode's tailored mesoporosity (which originates from the drying process). Whilst micropores assist in breaking down the Coulombic ordering of the ionic liquid electrolyte, the $20 \mathrm{~nm}$ wide pores facilitate the movement of the large chloroaluminate ions through the RGO. This effectively minimizes the inactive mass content of the electrode and more than compensates for the ordinary micropore volume of the graphene powder.
\end{abstract}

*e-mail: pedro.dacosta@kaust.edu.sa

Keywords: aluminum chloride, reduced graphene oxide, ionic liquid, cathode, battery, energy storage 


\section{INTRODUCTION}

The development of new energy storage technologies is of paramount importance in alleviating our dependence on fossil fuels and sustaining the rapidly expanding portable electronics market. ${ }^{1-3}$ Although Li-ion batteries (LIBs) have been the dominant option so far, their high production cost, together with the limited availability of lithium and its complex extraction process, present serious hurdles in satisfying the growing energy demands of Humanity. ${ }^{4,5}$ Consequently, research on different chemistries is gaining traction, particularly those based on abundant metals such as $\mathrm{Na}, \mathrm{Mg}$, Ca and Al. ${ }^{6-13}$

Aluminum is the most abundant metal in the Earth's crust and the mining of its ores is well-developed and cost-effective. Besides low toxicity, it presents numerous other advantages for application in batteries. ${ }^{14}$ For instance, the ions of aluminum are trivalent and have small ionic radii, allowing for high energy and high power density storage devices. In fact, its theoretical gravimetric and volumetric capacities are 2980 $\mathrm{mAh} \mathrm{g}^{-1}$ and $8040 \mathrm{mAh} \mathrm{cm}^{-3}$, respectively, with the latter representing the largest value among metal-ion batteries. ${ }^{13,15,16}$ Unfortunately, the highly charged nature of the $\mathrm{Al}^{3+}$ ions makes them strikingly hard to intercalate. ${ }^{17}$ Moreover, research into Al-based energy storage systems was historically afflicted by unsuitable electrolytes and the inactive aluminum oxide layer, which degraded battery performance. ${ }^{13}$ These issues have mostly been circumvented by employing ionic liquid (IL) electrolytes. Environmentally benign, ILs are characterized by low vapour pressure, high ionic conductivity, non-flammability, good thermal and electrochemical stabilities, and can be finely tuned with the appropriate choice of cations and anions. ${ }^{18,19}$ Accordingly, by mixing ILs and $\mathrm{AlCl}_{3}$, one obtains single valence chloroaluminate ions that allow for easy intercalation into graphitic materials and the dissolution of aluminum oxide layer. To date, 1-ethyl-3-methylimidazolium chloride $([\mathrm{EMIm}] \mathrm{Cl})$ has been the IL of choice and mixing it with $\mathrm{AlCl}_{3}$ yields a Lewis acid that can be used as an electrolyte in rechargeable aluminum chloride batteries (ACBs). ${ }^{20}$

The ACBs operation mechanism is fundamentally different from other metal-ion chemistries, which are generally of the rocking-chair type (e.g. Li-ion batteries). Whereas in metal-ion batteries, the ions intercalate into the anode during charging, and into the cathode during discharging, there is no such thing in ACBs. Generally, it is accepted that the working mechanism of ACBs with graphitic electrodes proceeds through the following half-reactions during charging and discharging at the cathode (eq. 1) and anode (eq. 2):

$$
\begin{gathered}
\mathrm{C}_{n}+\mathrm{AlCl}_{4}^{-} \rightleftharpoons \mathrm{C}_{\mathrm{n}}\left[\mathrm{AlCl}_{4}\right]+\mathrm{e}^{-} \\
4 \mathrm{Al}_{2} \mathrm{Cl}_{7}^{-}+3 \mathrm{e}^{-} \rightleftharpoons \mathrm{Al}+7 \mathrm{AlCl}_{4}^{-}
\end{gathered}
$$


Accordingly, $\mathrm{AlCl}_{4}^{-}$intercalates into the cathode only during charging (eq. 1), while the stripping of the electrodeposited Al occurs during discharging. This proceeds through the interconversion between $\mathrm{Al}_{2} \mathrm{Cl}_{7}^{-}$ and $\mathrm{AlCl}_{4}^{-}$ions (eq. 2).

Recent research on ACBs has been heavily focused on exploring carbon materials as cathodes (Table S1). ${ }^{20}$, $21,22,23$ Generally, it is believed that a high structural quality of graphitic carbons assist in improving the performance of ACBs. ${ }^{23-25}$ In previous work, we showed that the synthesis strategy and drying methods employed in the preparation of reduced graphene oxide (RGO) can significantly alter the electrochemical response of these materials. ${ }^{26,27}$ Herein, we show that using a critical point dried (CPD) reduced graphene oxide (elsewhere RGO_CPD) as an electrode material results in one of the highest capacities reported for an ACB. Despite having a much higher defect density than other carbons used in the ACB literature, the RGO_CPD cathode is not only performant but also very stable over a wide range of current densities. Furthermore, after a systematic study on the viability of different current collectors for ACB, we identified $\mathrm{Nb}$ as an excellent alternative to Ta, Mo and glassy carbon.

\section{METHODS}

\subsection{Materials synthesis}

Graphite powder (99\%, crystalline, 325 mesh, Alfa Aesar) was oxidized and exfoliated using the improved Hummers' method, as described elsewhere. ${ }^{27,28}$ The graphene oxide (GO) powder was subsequently dried, either in supercritical $\mathrm{CO}_{2}$ or in vacuo (VAC) at $60^{\circ} \mathrm{C}$, for 12 hours. The dried powders were then hydrothermally reduced at $180^{\circ} \mathrm{C}$, for 24 hours. Lastly, the reduced graphene oxide powders (RGO) were dried similarly to the parent GO powders, and dubbed RGO_CPD and RGO_VAC, respectively. ${ }^{26}$ Graphite was used as-received and as a control sample.

To prepare the electrolyte, $[\mathrm{EMIm}] \mathrm{Cl}$ was first annealed in a tube furnace, in vacuo, at $70{ }^{\circ} \mathrm{C}$ and for 16 hours, to remove residual water; this powder was then introduced into an Ar-filled glove box (<0.5 ppm $\mathrm{O}_{2},<0.5 \mathrm{ppm} \mathrm{H} \mathrm{H}_{2} \mathrm{O}$ ) without exposure to ambient conditions. Anhydrous $\mathrm{AlCl}_{3}$ powder was used as-received from the vendor (Alfa Aesar). With these, the $\mathrm{AlCl}_{3}:[\mathrm{EMIm}] \mathrm{Cl}=1.3\left(\mathrm{~mol} \mathrm{~mol}^{-1}\right)$ electrolyte was prepared inside the glove-box by slowly adding the $\mathrm{AlCl}_{3}$ to $[\mathrm{EMIm}] \mathrm{Cl}$. Mixing of the two powders produced a clear light yellow liquid through an exothermic reaction, as shown in Figure S1a. Finally, the obtained electrolyte was stirred at 1000 RPM, for 30 minutes and left to stand. 


\subsection{Materials characterization}

The structural analysis was performed by powder X-ray diffraction (XRD) on a Bruker D8 ADVANCE and using a Cu K $\mathrm{K}_{\alpha}$ radiation $\left(\lambda=1.54 \AA\right.$ ), at a scan rate of $5 \mathrm{deg} \min ^{-1}$ and increments of $0.02^{\circ}$. Raman spectra were recorded on a Witec alpha 300 RA with a $532 \mathrm{~nm}$ solid-state laser. In situ Raman spectroscopy was performed using a custom-built Swagelok electrochemical cell with a fitted quartz window. Scanning electron microscopy (SEM) was performed on a FEI Quanta 600, operated at 4 kV. Transmission electron microscopy (TEM) was performed on a Cs-corrected $\operatorname{Titan}^{3} \mathrm{G}^{2}$ (Thermo Fisher Scientific), operated at 80 kV, and equipped with a Gatan K2 direct electron detection camera. High resolution TEM images were acquired in dose fractionation mode for sample drift corrections. Energy dispersive X-ray spectroscopy (EDS) mapping was done in scanning TEM (STEM) mode, on a probe-corrected Titan Themis Z (Thermo Fischer Scientific), operated at $300 \mathrm{kV}$ and equipped with Super $\mathrm{X}$ detectors.

\subsection{Electrochemical measurements}

Electrochemical measurements were taken on a Bio-Logic VMP3 potentiostat, in a Swagelok twoelectrode cell configuration. The cells were assembled inside an Ar-filled glove box (LABstar, MBraun) using RGO_CPD, RGO_VAC or graphite and an Al foil (99.999\%, 0.25 mm, Sigma-Aldrich) as electrodes. The cathode was fabricated by mixing $80 \mathrm{wt} \%$ of active material (RGO_CPD, RGO_VAC or graphite), 10 wt\% polyvinylidene fluoride (PVDF) and $10 \mathrm{wt} \%$ acetylene black with $\mathrm{N}$-methyl-2-pyrrolidone (NMP). The obtained slurry was transferred into a vial and magnetically stirred for 24 hours for homogenization. A doctor blade was used to coat a $\mathrm{Nb}$ foil (19 $\mathrm{mm}$ in diameter and $0.25 \mathrm{~mm}$ thick) with $100 \mu \mathrm{m}$ of the slurry. After being dried in vacuo (10 mbar), at $100^{\circ} \mathrm{C}$ and for 16 hours, the electrodes were transferred to an Arfilled glovebox, taking care not to expose them to air. Three borosilicate microfiber filters (Grade GF/F, Whatman), soaked with $10 \mu \mathrm{l}$ of $\mathrm{AlCl}_{3}:[\mathrm{EMIm}] \mathrm{Cl}=1.3\left(\mathrm{~mol} \mathrm{~mol}^{-1}\right)$ electrolyte, were used as separators for each electrochemical cell. The filters were desiccated, at $150{ }^{\circ} \mathrm{C}$ in vacuo (10 mbar) and for 16 hours, in a tube furnace and subsequently introduced into the Ar-filled glove box, avoiding air exposure. Additionally, all cell components were dried inside the glove box, on a hotplate at $150{ }^{\circ} \mathrm{C}$ and for at least 12 hours. Electrochemical impedance spectroscopy (EIS) was carried out on a Bio-Logic VMP3 potentiostat from 10 $\mathrm{mHz}$ to $100 \mathrm{kHz}$, with an amplitude of $10 \mathrm{mV}$. Before each electrochemical assay, the cell was left to stand for 16 hours (in open circuit conditions) to properly wet the electrodes with the electrolyte. Afterwards, the cells were subjected to an activation step with cyclic voltammetry (CV), employing over 500 cycles at 
$20 \mathrm{mV} \mathrm{s}^{-1}(0.01-2.2 \mathrm{~V})$. The galvanostatic charge and discharge experiments were carried out at different current densities, ranging from $100 \mathrm{~mA} \mathrm{~g}^{-1}$ to $20000 \mathrm{~mA} \mathrm{~g}^{-1}$, and using a potential window of $0.01 \mathrm{~V}$ to 2.2 V. All electrochemical measurements were carried out at room temperature. All capacities, energy and power densities are reported per mass of the active material.

\section{RESULTS \& DISCUSSION}

In a previous study, we showed that the selection of the post-synthesis drying approach played a significant role in controlling the surface area, porosity and electrochemical response of RGOs. Indeed, a supercritical fluid drying approach allows to increase considerably the surface area and pore volume of an hydrothermally reduced GO, while also improving its electrochemical performance. ${ }^{26}$

Powder X-ray diffraction (XRD) was carried out to elucidate the structure of the RGO_CPD material. The XRD pattern, shown in Figure 1a, exhibits two broad peaks at $\sim 25^{\circ}$ and $\sim 44^{\circ}$, assigned to the (002) and (101) planes, respectively. The (002) peak position corresponds to an interlayer distance of $0.356 \mathrm{~nm}$, whereas its large full width at half-maximum (FWHM) is indicative of small crystallite sizes. As per the Scherrer relation, this was calculated as $2.13 \mathrm{~nm}$. Raman spectroscopy identified strong D- and G-bands at $1347 \mathrm{~cm}^{-1}$ and $1592 \mathrm{~cm}^{-1}$, respectively (Figure 1b). The D-band arises from the cumulative effect of the breathing motion of the $\mathrm{sp}^{2}$-bonded $\mathrm{C}$ atoms at places where the symmetry is broken, i.e. either at the edge of the graphene layers or at defect sites. ${ }^{29,} 30$ Therefore, a strong D-band in the RGO_CPD implies a high defect density and/or small crystallite sizes. The presence of the G-band confirms the graphitic character of the material, although its wide FWHM $\left(\sim 115 \mathrm{~cm}^{-1}\right)$, together with the high D- to G-band intensity ratio $\left(I_{D} / I_{G} \approx 1\right)$, are indicative of a low degree of graphitization, hence corroborating the XRD findings. ${ }^{31}$ 

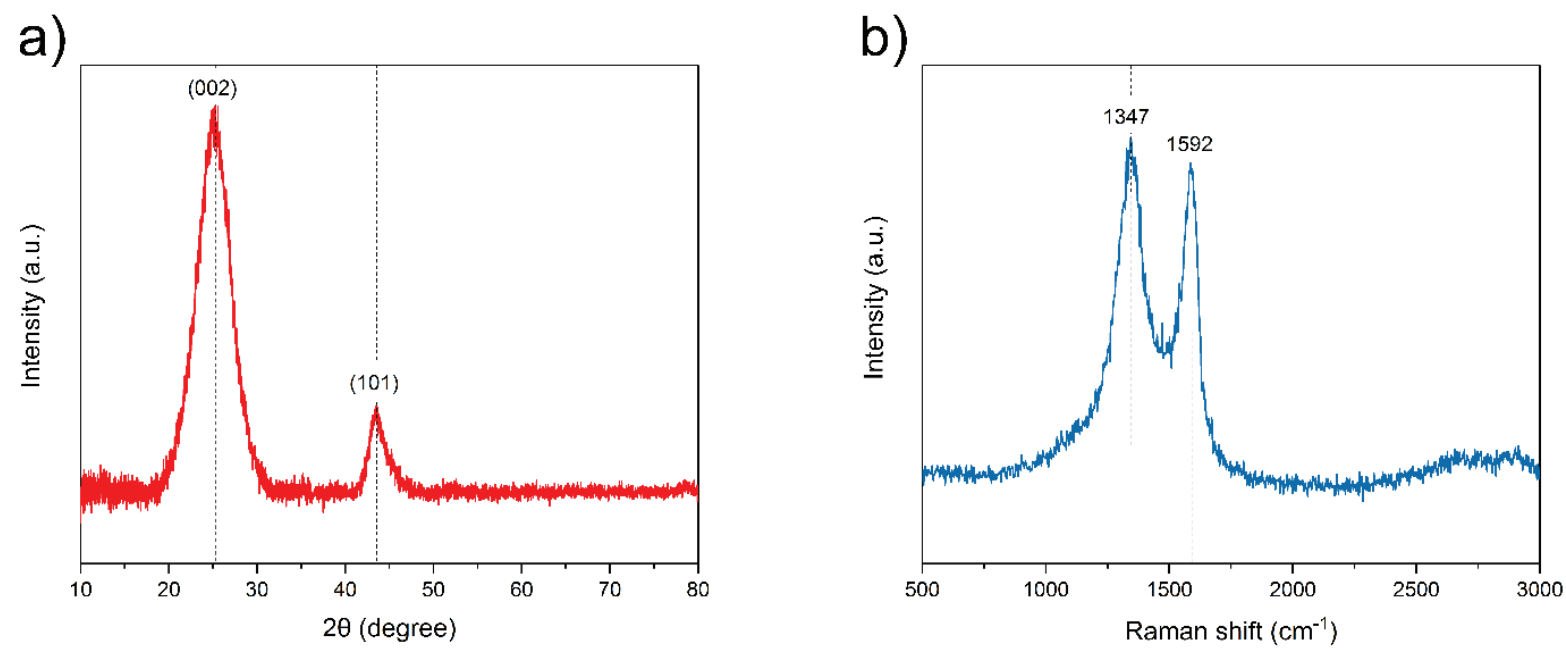

Figure 1. (a) XRD spectrum for the RGO_CPD; (b) Raman spectrum for the RGO_CPD.

Figure 2 presents typical electron micrographs of the RGO_CPD. From Figure $2 a$ it is observed that the RGO_CPD has a layered morphology with a fairly consistent separation of the corrugated basal planes. This was further confirmed by TEM which, in addition to wrinkled graphene layers, showed the highly disordered structure of the RGO_CPD sheets (Figure $\mathbf{2 b}$ ). A large defect density was observed using highresolution TEM (Figure 2c). From these and previous observations, ${ }^{26}$ we conclude that the RGO_CPD is a highly defective and porous material. Additionally, it has a high surface area, an expanded interlayer distance and small crystallite size. ${ }^{26}$ As it will be reasoned below, all these characteristics are thought to facilitate the wetting of the RGO_CPD-based cathode by the electrolyte and, consequently, to enable easy access of the large chloroaluminate ions to the redox active sites.
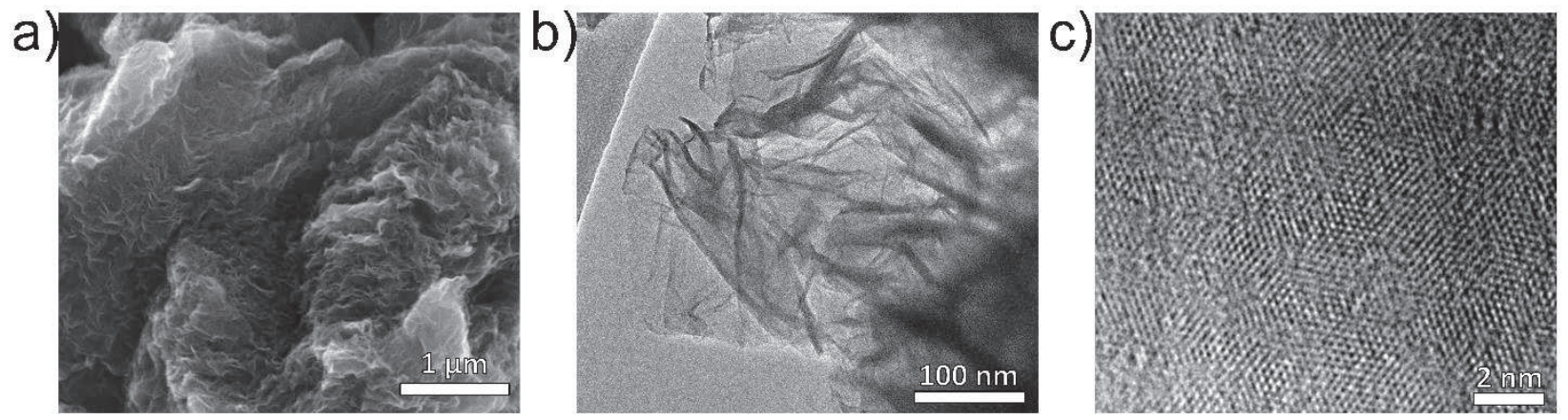

Figure 2. (a) SEM, (b) TEM and (c) HRTEM images of the RGO_CPD.

Following the structural characterization of the RGO_CPD, it was necessary to study the composition of the imidazolium-based electrolyte. Reversible electrodeposition of Al is possible only with the 
$\mathrm{AlCl}_{3}:[\mathrm{EMIm}] \mathrm{Cl}$ melts of molar ratios $>1$, a consequence of the partial $\mathrm{AlCl}_{4}^{-}$complexation into $\mathrm{Al}_{2} \mathrm{Cl}_{7}{ }^{-}$and subsequent interconversion between them. ${ }^{32,33}$ The presence of chloroaluminate ions was confirmed with Raman spectroscopy. In Figure $\mathbf{S} 1 \mathbf{b}$, the peaks at $310 \mathrm{~cm}^{-1}$ and $431 \mathrm{~cm}^{-1}$ are attributed to $\mathrm{Al}_{2} \mathrm{Cl}_{7}{ }^{-}$, whereas the peaks at $348 \mathrm{~cm}^{-1}$ and $597 \mathrm{~cm}^{-1}$ are assigned to $\mathrm{AlCl}_{4}^{-}$and $\mathrm{EMIm}^{+}$, respectively. ${ }^{20}$

While popular, chlorine-containing electrolytes readily corrode a large number of metals, including those typically used for LIBs. Thus, it is imperative to have current collectors that will not consume chloroaluminate ions through side-reactions. To this day, Mo, Ta, W and glassy carbon have all been successfully used as current collectors (Table S1). Some groups have also reported the use of $\mathrm{Ni}$, but we found that it exhibited strong redox peaks in the 1.0-1.5 V region (Figure S2a). ${ }^{23,34,35}$ We have also tested a carbon-coated $\mathrm{Cu}$ foil $(\mathrm{C}-\mathrm{Cu}$ ) and carbon paper, and observed that both exhibited a certain amount of activity in the chlorine-based electrolyte. Surprisingly, the best results were obtained with a Nb foil (Figures S2a, S2b and S3a). Inert up to $2.2 \mathrm{~V}$, this $4 \mathrm{~d}$ transition metal has an electrical resistivity of $15.2 \mathrm{x}$ $10^{-8} \Omega$, a mass density of $8.57 \mathrm{~g} \mathrm{~cm}^{-3}$, and is more abundant than Mo, $\mathrm{W}$ or Ta by an order of magnitude. ${ }^{14}$ All together, this makes $\mathrm{Nb}$ a very promising current collector for ACBs.

After the successful synthesis of the $\mathrm{AlCl}_{3}:[\mathrm{EMIm}] \mathrm{Cl}=1.3\left(\mathrm{~mol} \mathrm{~mol}^{-1}\right)$ electrolyte and selection of $\mathrm{Nb}$ as the current collector, we investigated the electrochemical performance of the RGO-based cathodes. Since the cathodes were fabricated by adding acetylene black and PVDF to the RGOs, we tested, separately, the electrochemical activity of these in the electrolyte (i.e. blank experiment). As shown in Figure S3b, their capacity contribution is negligible. Following this, and knowing that the presence of aluminum oxide can hinder the reduction reaction of metal salts, ${ }^{36}$ the need to perform an activation step for the assembled ACB cells was examined. Indeed, we saw that, when working at $20 \mathrm{mV} \mathrm{s}^{-1}$, the peak current increased with cycling (Figure S4). The gradual exposure of the Al surface allowed for a larger number of redox pairs and, consequently, larger capacity. ${ }^{37}$ Once the aluminum metal was fully exposed to the electrolyte, the peak current stabilized. Note that the Al foil was checked for dendrites formation and corrosion, before and after cycling. After 100 cycles at $100 \mathrm{mAh} \mathrm{g}^{-1}$, SEM imaging did not reveal changes to the Al surface (Figure S5). This concurs with previous claims of dendrite-free operation of $A C B$ in acidic $\mathrm{AlCl}_{3}:[\mathrm{EMIm}] \mathrm{Cl}$ melts. ${ }^{20}$, 
The galvanostatic charge and discharge curves of the RGO_CPD are shown in Figure 3a. The initial charge and discharge capacities are $212 \mathrm{mAh} \mathrm{g}^{-1}$ and $171 \mathrm{mAh} \mathrm{g}^{-1}$, respectively, with a Coulombic efficiency of $81 \%$. Remarkably, after 100 cycles, the discharge capacity remains at $148 \mathrm{mAh} \mathrm{g}^{-1}$, one of the highest values obtained for carbonaceous cathode materials ( $c f$. Table S1). The Coulombic efficiency does not change significantly with cycling (Figure 3b), implying that the discrepancy between charge and discharge capacities is not due to the formation of a solid-electrolyte interface (SEI). Instead, it is likely the result of ongoing side-reactions, possibly triggered by the presence of residual water in the electrolyte. ${ }^{20}$ Note that relatively low Coulombic efficiencies were also reported by other groups when using $\mathrm{AlCl}_{3}:[\mathrm{EMIm}] \mathrm{Cl}$ electrolytes at lower current densities. ${ }^{20,24,35}$ Further to this, none of the curves showed the characteristic strong plateaus that are common in LIBs (Figures 3a and S6).

Increasing the current density improved significantly both the Coulombic efficiency and cycling stability of the RGO_CPD cathode (Figure 3c). Capacity retention after 100 cycles was over $85 \%$ at $100 \mathrm{~mA} \mathrm{~g}^{-1}$, but it rapidly approached $\sim 100 \%$ at higher current densities (Figure S7a). In fact, from $500 \mathrm{~mA} \mathrm{~g}^{-1}$ to 20000 $\mathrm{mA} \mathrm{g}^{-1}$, the cathode showed Coulombic efficiencies of $>97 \%$. Capacities ranging from $120 \mathrm{mAh} \mathrm{g}^{-1}$ to 40 mAh g ${ }^{-1}$ were observed at current densities of $200 \mathrm{mAh} \mathrm{g}^{-1}$ to $20000 \mathrm{~mA} \mathrm{~g}^{-1}$, respectively (Figures 3c, S6 and S7b). At the end of the rate capability study (Figure 3c), and upon restoring the current density to 200 $\mathrm{mA} \mathrm{g}^{-1}$, the capacity of the battery remained high (115 $\mathrm{mAh} \mathrm{g}^{-1}$, corresponding to $96 \%$ capacity retention after 1000 cycles). The long-term stability was also tested at $1000 \mathrm{~mA} \mathrm{~g}^{-1}$ for 3000 cycles (Figure S8a), and at $10000 \mathrm{~mA} \mathrm{~g}^{-1}$ for 25000 cycles (Figure S8b). In both cases, the Coulombic efficiency was $100 \%$, with capacities of $99 \mathrm{mAh} \mathrm{g}^{-1}$ and $55 \mathrm{mAh} \mathrm{g}^{-1}$, respectively. No degradation was observed, a clear indication of the exceptional stability of the RGO_CPD cathode. The RGO_CPD cathode delivered an estimated energy density of $170 \mathrm{Wh} \mathrm{kg}^{-1}$ and a power density of $21 \mathrm{~kW} \mathrm{~kg}^{-1}$. 
a)

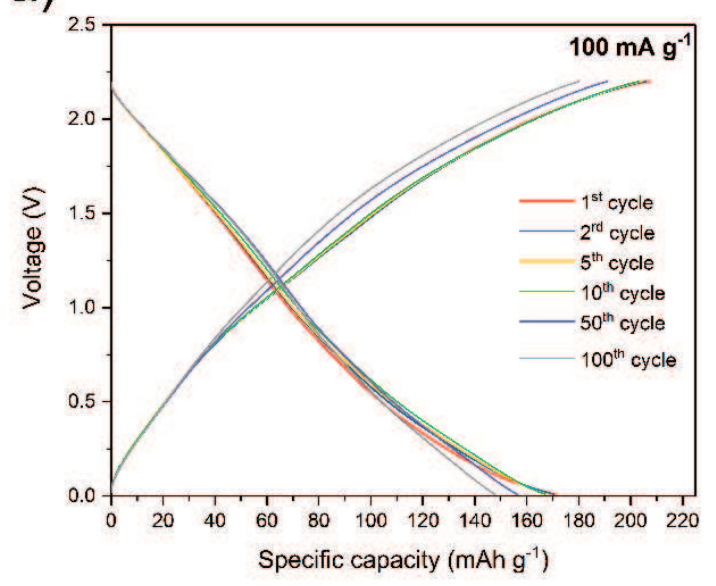

b)

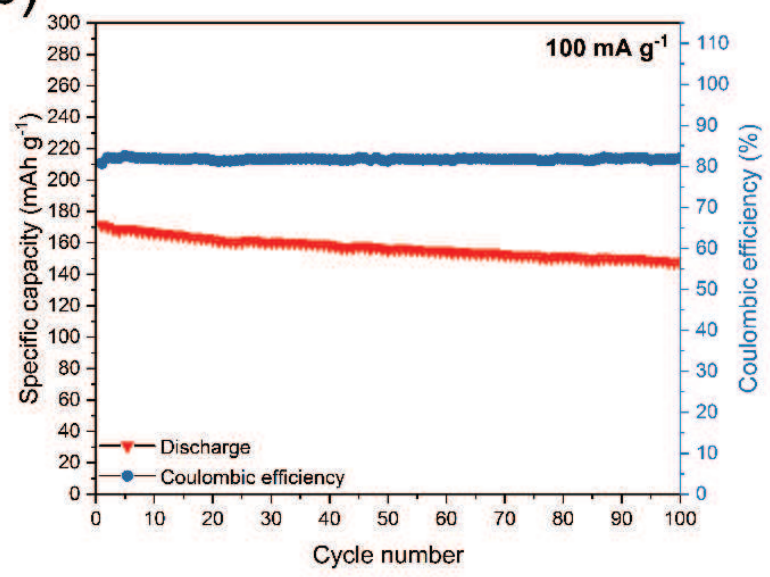

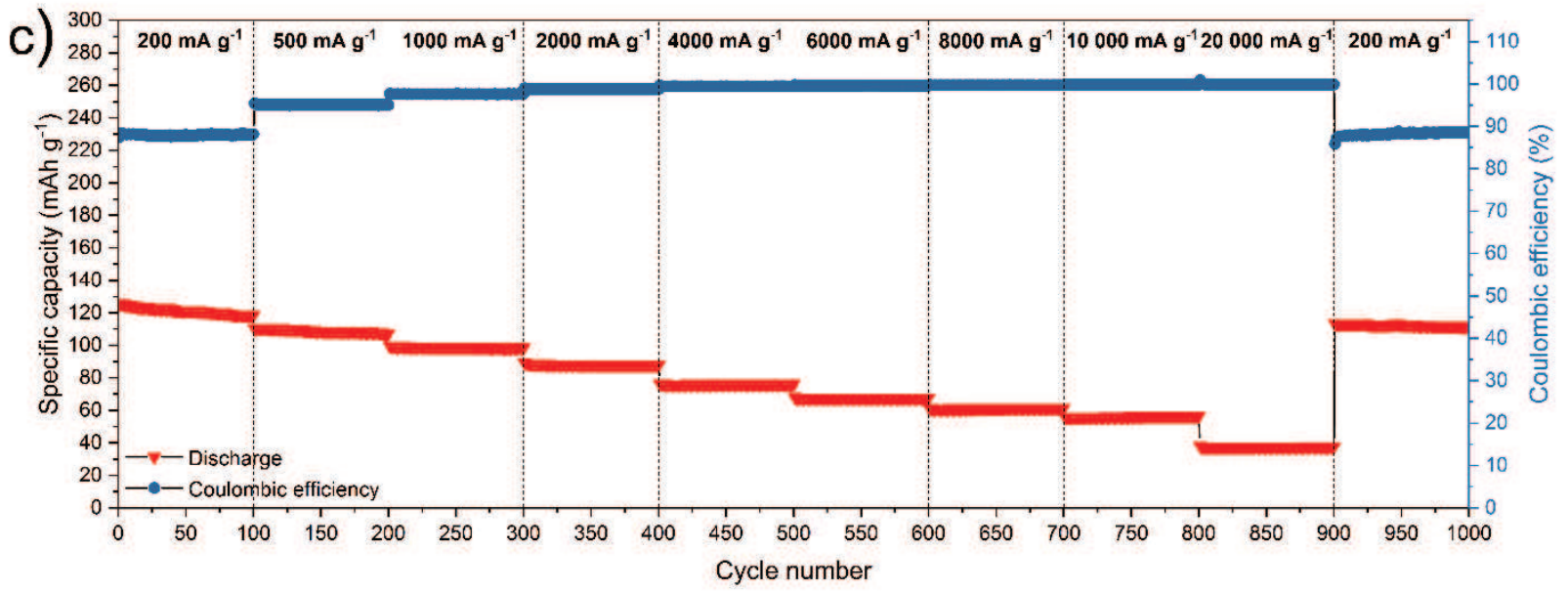

d)

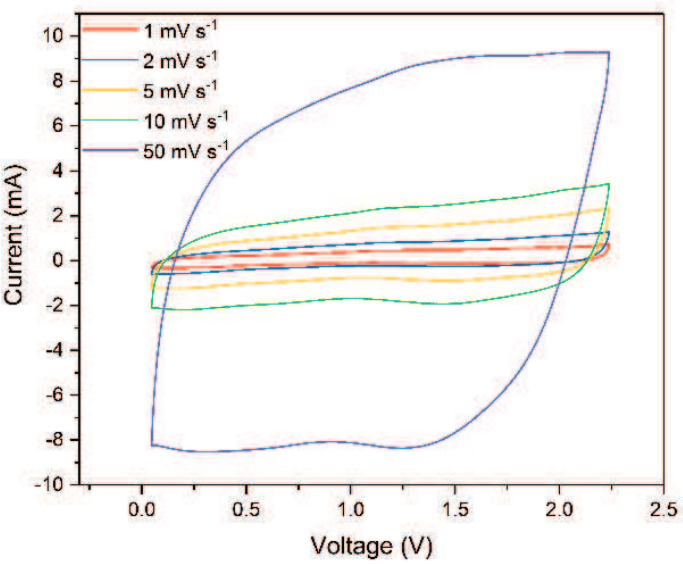

e)

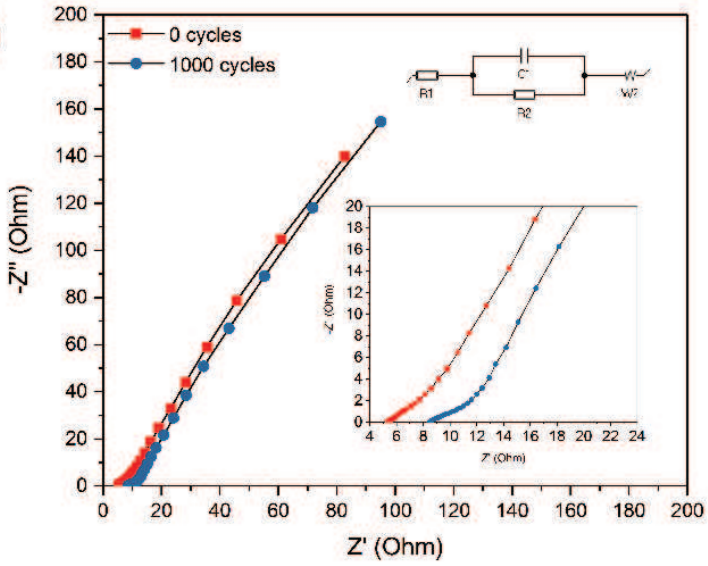

Figure 3. RGO_CPD electrochemical performance: (a) voltage profiles of $A C B$ at current density of $100 \mathrm{~mA} \mathrm{~g}^{-1}$; (b) cycling stability at current density of $100 \mathrm{~mA} \mathrm{~g}^{-1}$; (c) rate capability from $200 \mathrm{~mA} \mathrm{~g}^{-1}$ to $20000 \mathrm{~mA} \mathrm{~g}^{-1}$; (d) cyclic voltammograms at different voltage sweeps; (e) Electrochemical impedance spectroscopy of RGO_CPD before and after charge-discharge cycling, at $1000 \mathrm{~mA} \mathrm{~g}^{-1}$ for 1000 cycles with equivalent circuit inset. 
Cyclic voltammetry was performed to identify possible electrochemical reactions (Figure 3d). Only faint and broad redox couples were observed, confirming the observations of the charge-discharge galvanostatic curves. In fact, the profile at $50 \mathrm{mV} \mathrm{s}^{-1}$ was found to be similar to what is commonly seen in electrical double layer capacitance (EDLC) systems. ${ }^{41}$

To further understand the electrode kinetics, electrochemical impedance spectroscopy (EIS) was carried out. The Nyquist plots of RGO_CPD, shown in Figure 3e, consist of a depressed semi-circle in the highfrequency region, assigned to the charge transfer resistance $\left(R_{1}\right)$, and a slope in the low-frequency region, assigned to the semi-infinite diffusion or Warburg impedance $(W)$ of chloroaluminate ions at the electrode-electrolyte interface. The charge transfer resistance stays roughly the same ( $5 \Omega)$ after 1000 cycles, indicating fast electrode kinetics.

Following the electrochemical analysis, we investigated the nature of the ionic charge carriers. To this end, EDS mapping was carried out on cathode samples collected in charged and discharged states (Figure 4). The presence of both $\mathrm{Al}$ and $\mathrm{Cl}$ confirmed that chloroaluminate ions, rather than $\mathrm{Al}^{3+}$, were responsible for the operation of the battery. The distribution of these in the graphene flakes is widespread, which attests to the full diffusion of the ions. In the discharged state, the faint presence of $\mathrm{Al}$ and $\mathrm{Cl}$ is explained by trapping events in the micropores of the RGO_CPD.
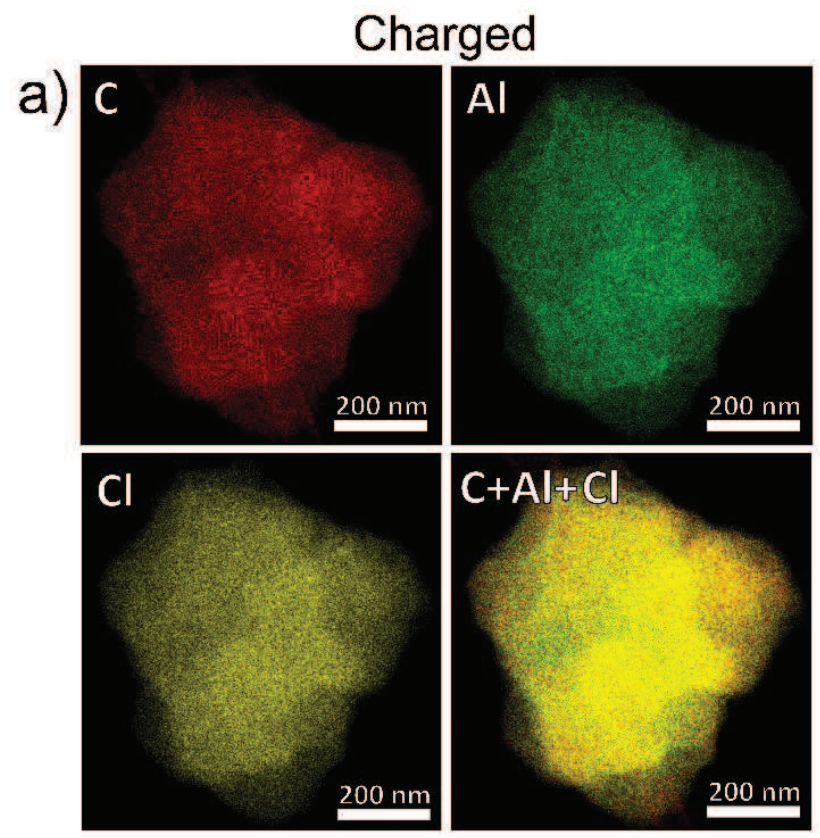
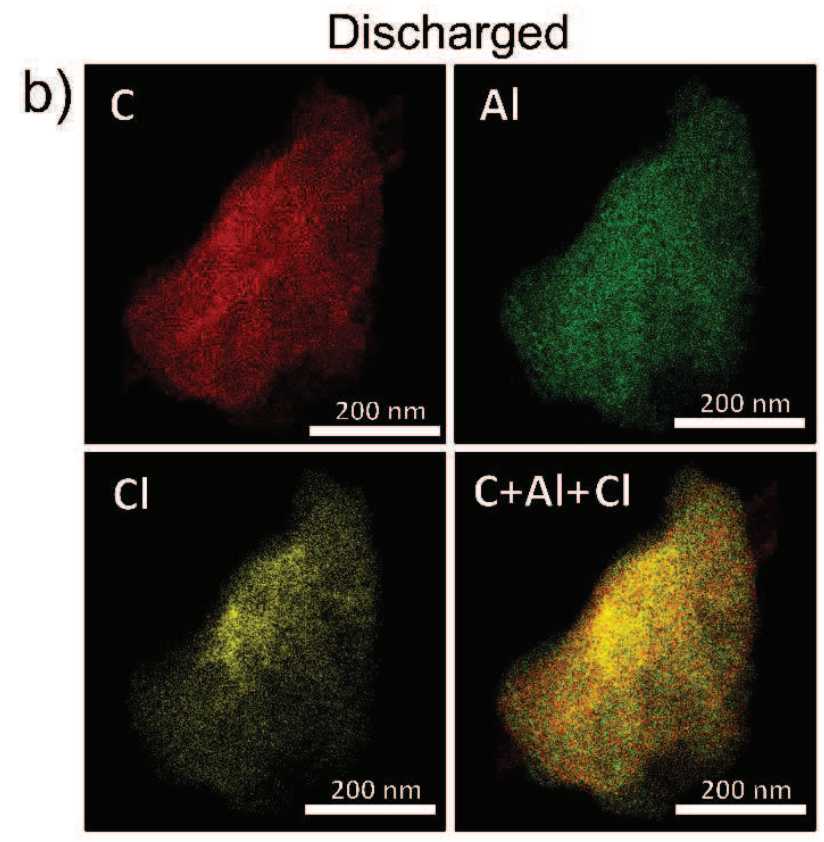

Figure 4. Chemical mapping of RGO_CPD flakes in charged (a) and discharged (b) states. 
Overall, the above results point towards a surface-based charge storage mechanism, therefore different from the intercalation processes that take place in LIBs. Given the porous morphology and the relatively high surface area of the RGO_CPD material, ${ }^{26}$ it is plausible to state that a large number of chloroaluminate ions can adsorb onto its surface, thereby circumventing the limitations inherent to a diffusion-limited intercalation process. To corroborate this hypothesis, in situ Raman spectroscopy and SEM imaging were performed. As shown in Figure S9a, the Raman spectrum of the interface between RGO_CPD and electrolyte is clearly the sum of individual cathode and electrolyte peaks, which show no significant variations in the position and broadening with respect to the cathode's pristine, charged and discharged states (Figure S9b). Additionally, a morphological comparison of the pristine and the cycled electrode's material did not identify visible changes in the carbonaceous flakes (Figures S10).

The response of the RGO_CPD as a material promoting surface-based charge storage has also been observed in other types of electrodes..$^{42}$ Upon reaching the critical size of a crystallite, the surface area increases, and the diffusion occurs only through very limited timescales, leading to a "pseudocapacitivelike" behavior. ${ }^{41}$ Analogous phenomena have been reported for similar battery chemistries, including those based on $\mathrm{Li}, \mathrm{Na}$ and $\mathrm{K} \cdot{ }^{43-47}$ It is important to emphasize, however, that the extrinsic pseudocapacitance of the RGO_CPD is not an inherent property of a graphitic material. In fact, it differs from intrinsically pseudocapacitive materials such as $\mathrm{RuO}_{2}$ and $\mathrm{MnO}_{2}$, as these do not exhibit any diffusion-controlled intercalation, irrespective of the morphology of the material. ${ }^{41,48}$

To better understand the electrochemical performance of the RGO_CPD, control experiments were carried out with ACBs that were assembled with two other active carbonaceous materials: 1) a RGO that was dried in vacuum, dubbed RGO_VAC, and 2) a graphite powder, used as the starting material for the preparation of both RGOs (i.e. CPD and VAC). The structural analysis of these two materials is presented in Figures S11a (XRD) and S11b (Raman). The XRD of the RGO_VAC shows broad peaks at $25^{\circ}$ and $44^{\circ}$ attributed to the (002) and (101) planes, respectively, whereas the diffractogram of the graphite is dominated by the sharp peak at $26^{\circ}$, assigned to the (002) planes. The Raman spectrum of RGO_VAC is characterized by two broad D- and G-bands, at $1322 \mathrm{~cm}^{-1}$ and $1581 \mathrm{~cm}^{-1}$, respectively, whereas that of graphite shows D-, G- and 2D-bands at $1344 \mathrm{~cm}^{-1}, 1571 \mathrm{~cm}^{-1}$ and $2689 \mathrm{~cm}^{-1}$, respectively. The electrochemical analysis of the graphite (Figure S11c, inset) showed clear intercalation/deintercalation of chloroaluminate ions. Despite this, with a discharge capacity of $11 \mathrm{mAh} \mathrm{g}^{-1}$ (Figure S11c), its electrochemical performance is remarkably poor. For the RGO_VAC, there is no apparent intercalation (Figure S11d, inset) and the displayed performance is slightly better, attaining $17 \mathrm{mAh} \mathrm{g}^{-1}$ (Figure S11d). 
Taking into account that the RGO_CPD and RGO_VAC have identical chemical signatures ${ }^{26}$ and similar pseudocapacitive-like responses, the much poorer electrochemical performance of the latter can only be attributed to their different morphological characteristics. In particular, between RGO_CPD 26 and RGO_VAC ${ }^{49}$, the values of the surface area and pore size are notably different (Table 1). Yet, it is the latter which is key to the superior electrochemical performance of the RGO_CPD. In fact, the importance of pore size is clearly manifested when comparing the results for RGO_CPD with other materials that have higher surface area and total pore volume, but lower mesoporosity (Table 1). The MTC31 has a surface area of $1490 \mathrm{~m}^{2} \mathrm{~g}^{-1}$ (vs $364 \mathrm{~m}^{2} \mathrm{~g}^{-1}$ for the RGO_CPD) and a total pore volume of $2.16 \mathrm{~cm}^{3} \mathrm{~g}^{-1}$ (vs. $1.17 \mathrm{~cm}^{3} \mathrm{~g}^{-1}$ ). Yet, at the $20^{\text {th }}$ cycle under $100 \mathrm{~mA} \mathrm{~g}^{-1}$, we observed that this material shows a discharge capacity of $\sim 107 \mathrm{mAh}$ $\mathrm{g}^{-1}$, whereas the RGO_CPD reaches $163 \mathrm{mAh} \mathrm{g}^{-1}$. The lower capacity of MTC31 can only be justified by the one order of magnitude lower mesopore volume when compared to that of the RGO_CPD. ${ }^{42}$ Therefore, although the surface area and porosity are clearly beneficial in improving the electrochemical performance (as seen by the $251 \mathrm{mAh} \mathrm{g}^{-1}$ capacity for ZTC vs. $163 \mathrm{mAh} \mathrm{g}^{-1}$ for RGO_CPD), the pore size distribution (micro/meso) seems to be another prominent variable to consider. ${ }^{50,51}$ In the case of RGO_CPD, ${ }^{26}$ the network of the predominantly $20 \mathrm{~nm}$ wide pores facilitates the movement of the large chloroaluminate ions and the proper wetting of the electrode, resulting in a lower inactive volume content of the electrode. ${ }^{52}$

Table 1 Relation between morphological differences and electrochemical performance of different carbon materials

\begin{tabular}{|c|c|c|c|c|}
\hline & RGO_CPD ${ }^{26}$ & RGO_VAC ${ }^{26}$ & MTC31 $^{42}$ & ZTC $^{42}$ \\
\hline Total surface area $\left(\mathrm{m}^{2} \mathrm{~g}^{-1}\right)$ & 364 & 39 & 1490 & 3510 \\
\hline Total pore volume $\left(\mathrm{mL} \mathrm{g}^{-1}\right)$ & 1.17 & 0.06 & 2.16 & 2.36 \\
\hline Micropore volume $\left(\mathrm{mL} \mathrm{g}^{-1}\right)$ & 0.023 & 0.005 & 0.51 & 1.4 \\
\hline Peak pore size $(\mathrm{nm})$ & 20 & $<2$ & 3.3 & 1.2 \\
\hline Peak pore volume $\left(\mathrm{mL} \mathrm{g}^{-1}\right)$ & 1.3 & 0.06 & 0.11 & 0.22 \\
\hline $\begin{array}{l}20^{\text {th }} \text { cycle discharge capacity at } \\
100 \mathrm{~mA} \mathrm{~g}^{-1}\left(\mathrm{mAh} \mathrm{g}^{-1}\right)\end{array}$ & 163 & 17 & $\sim 107$ & $\sim 250$ \\
\hline
\end{tabular}

\section{CONCLUSIONS}

A mesoporous reduced graphene oxide powder (RGO_CPD) was synthesized for use as the active material in an ACB cathode. The assembled electrode delivers one of the highest capacities reported for carbonaceous materials in ACBs (171 mAh g-1 and $107 \mathrm{mAh} \mathrm{g}^{-1}$ at current densities of $100 \mathrm{~mA} \mathrm{~g}^{-1}$ and 1000 
$\mathrm{mA} \mathrm{g}^{-1}$, respectively). In addition, the RGO_CPD has an outstanding cyclability, tested up to 25000 cycles. This excellent performance is attributed to the presence of mesopores, which grants easy pathways for electrolyte infiltration into the electrode, and allows a better utilization of the material. Moreover, the large electrolyte-electrode interface enables easy and fast charge transfer, resulting in high energy and power densities. We also demonstrated the viability of $\mathrm{Nb}$ as a current collector. These findings show that tailoring the porosity and surface area of carbon-based electrode materials is a decisive factor for the electrochemical performance of aluminum batteries.

\section{REFERENCES}

1. B. Dunn, H. Kamath and J.-M. Tarascon, Science, 2011, 334, 928-935.

2. C. Liu, F. Li, L.-P. Ma and H.-M. Cheng, Advanced Materials, 2010, 22, E28-E62.

3. H. Ibrahim, A. Ilinca and J. Perron, Renewable and Sustainable Energy Reviews, 2008, 12, 12211250.

4. J.-M. Tarascon, Philosophical Transactions of the Royal Society A: Mathematical, Physical and Engineering Sciences, 2010, 368, 3227-3241.

5. B. Scrosati and J. Garche, Journal of Power Sources, 2010, 195, 2419-2430.

6. N. Yabuuchi, K. Kubota, M. Dahbi and S. Komaba, Chemical Reviews, 2014, 114, 11636-11682.

7. M. D. Slater, D. Kim, E. Lee and C. S. Johnson, Advanced Functional Materials, 2013, 23, 947-958.

8. M. M. Huie, D. C. Bock, E. S. Takeuchi, A. C. Marschilok and K. J. Takeuchi, Coordination Chemistry Reviews, 2015, 287, 15-27.

9. J. W. Choi and D. Aurbach, Nature Reviews Materials, 2016, 1, 16013.

10. A. Ponrouch and M. R. Palacin, Current Opinion in Electrochemistry, 2018, 9, 1-7

11. A. L. Lipson, B. Pan, S. H. Lapidus, C. Liao, J. T. Vaughey and B. J. Ingram, Chemistry of Materials, 2015, 27, 8442-8447.

12. A. Eftekhari and P. Corrochano, Sustainable Energy \& Fuels, 2017, 1, 1246-1264.

13. G. A. Elia, K. Marquardt, K. Hoeppner, S. Fantini, R. Lin, E. Knipping, W. Peters, J.-F. Drillet, S. Passerini and R. Hahn, Advanced Materials, 2016, 28, 7564-7579.

14. CRC Handbook of Chemistry and Physics 90th Edition, CRC Press, 2010.

15. K. Li, Y. Shao, S. Liu, Q. Zhang, H. Wang, Y. Li and R. B. Kaner, Small, 2017, 13, 1700380.

16. M.-C. Lin, M. Gong, B. Lu, Y. Wu, D.-Y. Wang, M. Guan, M. Angell, C. Chen, J. Yang, B.-J. Hwang and H. Dai, Nature, 2015, 520, 324.

17. K. Li, Y. Shao, S. Liu, Q. Zhang, H. Wang, Y. Li and R. B. Kaner, Small, 2017, 13, 1700380.

18. C. Zhong, Y. Deng, W. Hu, J. Qiao, L. Zhang and J. Zhang, Chemical Society Reviews, 2015, 44, 74847539.

19. M. Watanabe, M. L. Thomas, S. Zhang, K. Ueno, T. Yasuda and K. Dokko, Chemical Reviews, 2017, 117, 7190-7239.

20. M.-C. Lin, M. Gong, B. Lu, Y. Wu, D.-Y. Wang, M. Guan, M. Angell, C. Chen, J. Yang, B.-J. Hwang and H. Dai, Nature, 2015, 520, 324-328.

21. H. Sun, W. Wang, Z. Yu, Y. Yuan, S. Wang and S. Jiao, Chemical Communications, 2015, 51, 1189211895.

22. Y. Wu, M. Gong, M.-C. Lin, C. Yuan, M. Angell, L. Huang, D.-Y. Wang, X. Zhang, J. Yang, B.-J. Hwang and H. Dai, Advanced Materials, 2016, 28, 9218-9222. 
23. H. Chen, F. Guo, Y. Liu, T. Huang, B. Zheng, N. Ananth, Z. Xu, W. Gao and C. Gao, Advanced Materials, 2017, 29, 1605958.

24. D.-Y. Wang, C.-Y. Wei, M.-C. Lin, C.-J. Pan, H.-L. Chou, H.-A. Chen, M. Gong, Y. Wu, C. Yuan, M. Angell, Y.-J. Hsieh, Y.-H. Chen, C.-Y. Wen, C.-W. Chen, B.-J. Hwang, C.-C. Chen and H. Dai, Nature Communications, 2017, 8, 14283.

25. L. Zhang, L. Chen, H. Luo, X. Zhou and Z. Liu, Advanced Energy Materials, 2017, 7, 1700034.

26. A. Alazmi, O. El Tall, S. Rasul, M. N. Hedhili, S. P. Patole and P. M. F. J. Costa, Nanoscale, 2016, 8, 17782-17787.

27. S. Rasul, A. Alazmi, K. Jaouen, M. N. Hedhili and P. M. F. J. Costa, Carbon, 2017, 111, 774-781.

28. A. Alazmi, S. Rasul, S. P. Patole and P. M. F. J. Costa, Polyhedron, 2016, 116, 153-161.

29. Y. Wang, D. C. Alsmeyer and R. L. McCreery, Chemistry of Materials, 1990, 2, 557-563.

30. J. Smajic, A. Alazmi, S. P. Patole and P. F. J. Costa, RSC Advances, 2017, 7, 39997-40004.

31. A. Yoshida, Y. Kaburagi and Y. Hishiyama, Carbon, 2006, 44, 2333-2335.

32. C. J. Dymek, J. L. Williams, D. J. Groeger and J. J. Auborn, Journal of The Electrochemical Society, 1984, 131, 2887-2892.

33. P. K. Lai and M. Skyllas-Kazacos, Journal of Electroanalytical Chemistry and Interfacial Electrochemistry, 1988, 248, 431-440.

34. H. Chen, H. Xu, S. Wang, T. Huang, J. Xi, S. Cai, F. Guo, Z. Xu, W. Gao and C. Gao, Science Advances, 2017, 3.

35. X. Yu, B. Wang, D. Gong, Z. Xu and B. Lu, Advanced Materials, 2016, 29, 1604118.

36. T. Jiang, M. J. Chollier Brym, G. Dubé, A. Lasia and G. M. Brisard, Surface and Coatings Technology, 2006, 201, 1-9.

37. S. Choi, H. Go, G. Lee and Y. Tak, Physical Chemistry Chemical Physics, 2017, 19, 8653-8656.

38. M. Walter, K. V. Kravchyk, C. Böfer, R. Widmer and M. V. Kovalenko, Advanced Materials, 0, 1705644.

39. J. J. Auborn and Y. L. Barberio, Journal of The Electrochemical Society, 1985, 132, 598-601.

40. Q. Li and N. J. Bjerrum, Journal of Power Sources, 2002, 110, 1-10.

41. T. Brousse, D. Bélanger and J. W. Long, Journal of The Electrochemical Society, 2015, 162, A5185A5189.

42. N. P. Stadie, S. Wang, K. V. Kravchyk and M. V. Kovalenko, ACS Nano, 2017, 11, 1911-1919.

43. S. H. Ha, Y. S. Jeong and Y. J. Lee, ACS Applied Materials \& Interfaces, 2013, 5, 12295-12303.

44. G. Ali, A. Mehmood, H. Y. Ha, J. Kim and K. Y. Chung, Scientific Reports, 2017, 7, 40910.

45. W. Wang, J. Zhou, Z. Wang, L. Zhao, P. Li, Y. Yang, C. Yang, H. Huang and S. Guo, Advanced Energy Materials, 2018, 8, 1701648.

46. R. Mukherjee, A. V. Thomas, D. Datta, E. Singh, J. Li, O. Eksik, V. B. Shenoy and N. Koratkar, Nature Communications, 2014, 5, 3710.

47. R. Mukherjee, A. V. Thomas, A. Krishnamurthy and N. Koratkar, ACS Nano, 2012, 6, 7867-7878.

48. P. Simon, Y. Gogotsi and B. Dunn, Science, 2014, 343, 1210-1211.

49. A. Alazmi, O. E. Tall, M. N. Hedhili and P. M. F. J. Costa, Inorganica Chimica Acta, 2018, 482, 470477.

50. S. Lin, C. Zhang, Z. Wang, S. Dai and X. Jin, Advanced Energy Materials, 2017, 7, 1700766.

51. C. Zhang, R. He, J. Zhang, Y. Hu, Z. Wang and X. Jin, ACS Applied Materials \& Interfaces, 2018, 10, 26510-26516.

52. N. Mahmood, T. Tang and Y. Hou, Advanced Energy Materials, 2016, 6, 1600374. 